\title{
Selection of resistant species of indoor plants for the health improvement the air environment of interiors
}

\author{
Andrey Tsitsilin ${ }^{1 *}$, and Tatyana Fateeva ${ }^{2}$ \\ ${ }^{1}$ All-Russian research institute medicinal and aromatic plants, laboratory of the Botanical Garden, \\ Grina str.7, 117216, Moscow, Russia \\ ${ }^{2}$ All-Russian research institute medicinal and aromatic plants, Toxicology department, Grina str.7, \\ 117216, Moscow, Russia
}

\begin{abstract}
Our studies show that at low illuminance, close to the light compensation point, plants of all studied species (Plectranthus amboinicus (Lour.) Spreng, Rhoicissus rhomboidea (E. Mey. ex Harv.) Planch., Elettaria cardamomum (L.) Maton) have a smaller total leaves area and low decorative qualities, and they have not antimicrobial activity. Plants grown under illuminance from 500 to 2000 lux, depending on the species, form a large above-ground biomass, live several times longer, have a pronounced phytoncidal effect (antimicrobal activity) on air microflora and Staphylococcus aureus. The maximum phytoncidal activity of E. cardamomum, $P$. amboinicus and $R$. rhomboidea are observed at an illuminance of 2000 lux (respectively $29 \%, 36 \%$ and $24 \%$ ). Phytoncidal activity decreases 2-3 times with a decline in the illuminance level to 500 lux, and in Indian borage, as a more light-loving plant, it disappears altogether. Phytoncidal activity of $P$. amboinicus(Indian borage) is $32 \%$ in relation to Staphylococcus aureus strain 209- P. Phytocompositions from resistant species of indoor plants reduce the number of microorganisms in the air of classrooms of secondary school by $45 \%-58 \%$, and ones of primary school - by 5.2-7.3 times.
\end{abstract}

\section{Introduction}

Interest of using of plants in interior landscaping in Russia and the world is constantly at a high level. This is explained by the many positive effects observed with this use of plants: improvement of the surrounding air environment by increasing the content of beneficial negative and reducing the concentration of harmful plus air ions, reducing the content of dust and harmful gaseous substances (carbon monoxide, nitrogen and sulfur oxides, formaldehyde, benzene, etc.), increasing air humidity, decreasing the number of pathogenic microorganisms, etc. In addition, plants have a beneficial effect on the psychoemotional sphere of a person by their appearance, help relieve physical and mental fatigue, the quickest way out of people from stressful conditions. Compositions of plants distract from

* Corresponding author: fitovit@gmail.com 
thoughts of ailments in a sick person, thereby increasing the effectiveness of treatment, and healthy people are less physically and mentally tired. Therefore, air quality in homes, offices, schools, kindergartens, medical institutions or other private and public buildings where people spend most of their lives is one of the most important parameters for a healthy lifestyle and well-being.

Scientists have searched the influence of plants in the reduction in the air of the interiors where they grow, harmful gaseous impurities that appear in the rooms, due to the use of finishing materials in construction (varnishes, chipboards, linoleums, paints, etc.) or due to external sources air pollution [1-5]. NASA scientists have proven the effectiveness of using more than 30 species of indoor plants in air pollution with harmful chemical compounds: benzene, formaldehyde, trichloroethanol, carbon monoxide, xylene, toluene [6-8].

The phytoncidal activity of plants was also found, i.e. a decrease in the number of pathogenic microorganisms in the air around them. Thus, it was shown that under the influence of volatile myrtle phytoncides, the number of colonies of air microflora from the Sarcinum decreases by $20-30 \%$, Bacillus by $30-40 \%$, Micrococcus by $60-70 \%$, and Staphylococcus aureus and Staphylococcus epidermidis by $25-30 \%$. The overall decrease in the number of air bacteria compared to the control level was about $50 \%[9,10]$.

Several studies have shown that the more plants there are in the room, the better they purify the air $[11,12]$. Volatile phytoorganic substances of living plants, or phytoncides, not only suppress the growth and development of harmful bacteria and fungi that live in the air, but also have a positive therapeutic effect on a different systems of the human body: cardiovascular, respiratory, etc.

Solving the problems of improving the health of the population, especially the townspeople, has always been relevant. Recently, due to the deterioration of the environmental situation, they have acquired a more acute focus. Most of their time, up to $70 \%$ or more, people spend indoors. The general level of air pollution inside buildings exceeds the level of atmospheric air pollution by 1.4-4 times, depending on the degree of air pollution, the area of location and the intensity of internal sources of pollution [13]. Also, enclosed spaces are characterized by the absence or limited action of natural factors suppressing pathogenic, air microflora, and the presence of a large number of people in schools, universities, kindergartens, clinics, etc., accelerates the growth of the number of microorganisms in the air.

In confined rooms during the autumn-winter period, illuminance is one of the important critical factors. The main limiting factors in growing plants in most premises (educational institutions, hospitals, apartments, offices, etc.) are low light (especially in the autumnwinter period), low air humidity $(20-40 \%)$ and high temperatures $\left(+18-20^{\circ} \mathrm{C}\right.$ and higher) throughout the year, without a period of relatively low winter temperatures. We believe that one of the main criteria for the successful introduction of plants indoors is the long-term preservation of its decorative qualities by the plant (at least a year), i.e. the presence of a sufficient number of shoots, leaves that have typical sizes and colors for the species, and therefore plants have a high phytoncidal activity. We have developed a new approach to the use of plants "ecological phytodesign" or "ecological aerofitotherapy" allows you to create long-term effective phytocompositions indoors [14]. We have previously discovered the phytoncidal activity of Plectranthus amboinicus (Lour.) Spreng, Rhoicissus rhomboidea (E. Mey. Ex Harv.) Planch., Elettaria cardamomum (L.) Maton against air microflora and Staphylococcus aureus strain 209-P [15, 16].

\section{Materials and methods}

The biological characteristics of the growth of three plant species belonging to three groups in relation to light were studied. The light-loving Indian borage (Plectranthus amboinicus 
(Lour.) Spreng), the shade-tolerant glossy forest grape (Rhoicissus rhomboidea (E. Mey.ex Harv.) Planch.) and the shade-loving true cardamom (Elettaria cardamomum (L.) Maton). The plants were taken from the collection of the Botanical Garden of the All-Russian Scientific Research Institute of Medicinal and Aromatic Plants. The plants were grown in vessels with a capacity of $1 \mathrm{~L}$, were placed in boxes, where, using an artificial light source (DRLF-400 lamp) and shading materials (gauze, lutrasil), illuminance of 2000, 500 and 100 lux was created for 12 hours a day. In each variant, the plants were placed in 4 replicates. Biometric parameters (height, number and size of leaves, plant total leaves area) were measured once every fifteen days.

To determine the phytoncidal activity, the plants were placed in plexiglass boxes $0.5 \mathrm{x}$ $0.5 \times 0.7 \mathrm{~m}$ in size. In the upper part of the box, Petri dishes with a solid nutrient medium (MPA) with microorganisms infected from the air were placed on a grid upside down. A control box of the same size was placed in exactly the same vessel with soil, but without a plant. The boxes were covered with a plexiglass sheet. The illuminance of the studied variants was created in 2000, 500 and 100 lux. Infection of sterile Petri dishes with microorganisms of the air environment was carried out by the conventional sedimentation method [17]. Petri dishes with a solid nutrient medium were left in the room open for 30 min, then they were closed and 4 dishes were placed to control the infection in a thermostat at $+36^{\circ} \mathrm{C}$, the remaining dishes were placed upside down on a retractable grid located at the top of the box. Petri dishes were removed from the experimental and control boxes 1 hour, 2 hours, 4, 6, and 24 hours after planting and placed in a thermostat at a temperature of + $36^{\circ} \mathrm{C}$. After 24 hours of incubation in a thermostat, each dish was removed and the colonies were counted. Gram-positive bacteria of Staphylococcus aureus 209-P were used as a pathogenic test microorganism. A suspension of bacteria was prepared in isotonic chloride solution according to a bacterial turbidity standard of 10 Units $\left(10^{9}\right.$ microbial bodies / ml $)$ and a series of decreasing dilutions of the suspension of bacteria was made so that $0.2 \mathrm{ml}$ of suspension contained from 100 to 300 bacteria. In each Petri dish with MPA, $0.2 \mathrm{ml}$ of a titrated culture of Staphylococcus aureus is added and triturated with a spatula, then 4 dishes were placed to control infection in a thermostat at $+36^{\circ} \mathrm{C}$, the rest were placed upside down on a sliding grid located at the top of the box. Petri dishes were removed from the experimental and control boxes 1 hour, 2 hours, 4, 6 and 23 hours after planting and placed in a thermostat at $+36^{\circ} \mathrm{C}$. After 24 hours, the Petri dishes were removed from the incubator and the colonies were counted.

The indicator of phytoncidal activity is the percentage of the relative decrease in the number of microorganisms in the experimental box compared to the control one. Phytoncidal activity (FA) shows a relative decrease in the number of microorganisms in the experiment in comparison with the control, i.e. what percentage of microorganisms die when exposed to plant phytoncides. The assessment of the phytoncidal activity of plants (FA) was calculated using the formula:

$$
F A=((K-E) / K) 100 \% \text {, }
$$

where $K$ is the number of microorganisms in the control, $E$ is the number of microorganisms in the experiment.

The phytoncidal activity in the Indian borage and glossy forest grape were determined 1 month after the start of the experiment, and in true cardamom - after 3 months. When determining the effectiveness of plants in educational institutions, phytocompositions were placed in 11 schools in Moscow. In each school, the phytocomposition was placed in the experimental classrooms of secondary and primary schools. The volume of each classroom was 166-184 m3. As controls, we took adjacent classrooms of the same size and with children of the same age. 
Due to the fact that plants have phytogenic fields, within which their phytoncidal properties are most pronounced, and also to obtain an objective picture of the average microbial air pollution of classes, 5 open Petri dishes with a solid nutrient medium (meatpeptone agar) were placed in each classroom, at the corners of the one and in the center. Petri dishes were left open in the classroom for $30 \mathrm{~min}$, then they were closed and placed in a thermostat at a temperature of $+36^{\circ} \mathrm{C}$. After 24 hours of incubation in a thermostat, each dish was removed and the colonies were counted. To obtain data on the efficiency of phytocompositions in dynamics, the number of microorganisms in the air was determined in spring: one month after the phytocompositions were installed and 50 days later, as well as in late autumn - more than 8 months after phytocompositions were installed.

Allergic reactions in children and teachers to the placed phytocompositions have determined by oral questioning and visual examination.

\section{Results and discussion}

Our studies to study the growth and development, as well as the phytoncidal activity of indoor plants, depending on different levels of illuminance, show that at low illuminance (100 lux), and in the autumn-winter period, in the light zone of Moscow, it is observed during November-January, plants of all studied species have a smaller leaf surface and low decorative qualities, and they don't have phytoncidal activity. Plants grown under illuminance from 500 to 2000 lux, depending on the species, form a large above-ground biomass, live several times longer, have a pronounced phytoncidal effect against pathogenic microorganisms in the indoor air.

First of all, about 2-3 weeks after the start of the experiment, differences in the growth of the aerial part of the Indian borage begin to appear. Plants have a lower height and number of leaves in the variant with a minimum illuminance of 100 lux. After 3-4 weeks, plants of different varieties begin to differ not only in the number of leaves, but also in their size. The highest aboveground biomass is observed in specimens grown at 2000 lux illuminance. They have a higher height, they also have the maximum number of leaves on the plant. At a high level of illuminance, larger leaves are formed, which in length and width are $65-95 \%$ higher than those of plants grown at lower levels of illuminance. An important criterion for the decorative properties and phytoncidal activity of a plant is the area of their leaves surface, which reaches its maximum values at an illuminance of 2000 lux and more by 3.8-19.7 times in plants growing at a lower illuminance of 500 and 100 lux, respectively.

Approximately 25-40 days after the start of the experiment, in the variant with an illuminance level of 100 lux, all shoots of the second order die off in the P. amboinicus. The plants of Indian borage are completely killed in 1.5-2.5 months at an illuminance level of 100 lux, and after 3.5-5 months, the death of plants is observed even at an illuminance of 500 lux.

Table 1. Biometric parameters of the studied species depending on the level of illuminance *.

\begin{tabular}{|l|l|c|c|c|c|c|}
\hline $\begin{array}{l}\text { Illuminance } \\
\text { level, lux }\end{array}$ & Plant species & $\begin{array}{l}\text { Plant } \\
\text { height, cm }\end{array}$ & $\begin{array}{l}\text { Number } \\
\text { of leaves/ } \\
\text { plant }\end{array}$ & $\begin{array}{l}\text { Average } \\
\text { leaf } \\
\text { length, cm }\end{array}$ & $\begin{array}{l}\text { Average } \\
\text { leaf width, } \\
\text { cm }\end{array}$ & $\begin{array}{l}\text { Average total } \\
\text { leaves area } \\
\text { cm2 / plant }\end{array}$ \\
\hline \multirow{3}{*}{2000} & P. amboinicus & $23.8 \pm 2.5$ & $15.1 \pm 1.9$ & $8.2 \pm 0.3$ & $5.8 \pm 0.2$ & $477.5 \pm 50.2$ \\
\cline { 2 - 7 } & R.rhomboidea & $39.8 \pm 4.6$ & $13.3 \pm 1.5$ & $7.5 \pm 1.0$ & $8.6 \pm 0.4$ & $504.6 \pm 51.7$ \\
\cline { 2 - 7 } & E.cardamomum & $18.7 \pm 1.6$ & $10.3 \pm 1.2$ & $14.2 \pm 1.1$ & $3.9 \pm 0.3$ & $362.9 \pm 37.1$ \\
\hline 500 & P. amboinicus & $13.8 \pm 1.4$ & $12.6 \pm 2.1$ & $4.2 \pm 0.7$ & $3.1 \pm 0.5$ & $126.5 \pm 15.7$ \\
\cline { 2 - 7 } & R.rhomboidea & $15.8 \pm 2.7$ & $3.5 \pm 0.9$ & $7.2 \pm 0.6$ & $7.4 \pm 1.2$ & $119.7 \pm 12.1$ \\
\cline { 2 - 7 } & E.cardamomum & $18.1 \pm 1.3$ & $5.8 \pm 0.4$ & $13.3 \pm 1.1$ & $3.6 \pm 0.4$ & $175.1 \pm 19.8$ \\
\hline
\end{tabular}




\begin{tabular}{|l|l|c|c|c|c|c|}
\hline 100 & P. amboinicus & $13.4 \pm 1.6$ & $2.1 \pm 0.4$ & $4.3 \pm 0.9$ & $3.5 \pm 0.6$ & $24.2 \pm 5.7$ \\
\cline { 2 - 7 } & R.rhomboidea & $9.6 \pm 0.8$ & $2.3 \pm 0.8$ & $5.4 \pm 1.9$ & $5.0 \pm 1.0$ & $36.5 \pm 6.9$ \\
\cline { 2 - 7 } & E.cardamomum & $18.2 \pm 1.5$ & $5.5 \pm 0.4$ & $11.5 \pm 0.9$ & $2.8 \pm 0.3$ & $112.4 \pm 14.1$ \\
\hline
\end{tabular}

* The biometric parameters of $P$. amboinicus are shown 1 month after the start of the experiment, R. rhomboidea - after 2 months, E. cardamomum - after 6 months.

In shade-tolerant glossy forest grape differences begins to appear both in the number of leaves and in the length of shoots at different levels of illuminance, by the end of the eighth week. And two months after the start of the experiment, the differences between the variants in the aerial part of the plant (plant height, number of leaves and leaves area) become significant. Plants become 2.5-4.1 times taller, the leaves surface increases 4.6-13.8 times at a maximum illumination of 2000 lux.

In the shade-loving type of true cardamom, external signs of a lack of light in the variant with a minimum level of illuminance: the formation of a smaller number of leaves is observed after 2 months, and yellowing of the lower leaves begins to appear much later, only at the end of the fifth month of the experiment. After another month, significant differences are observed in the average number of leaves per plant and the total leaf area. Thus, at an illuminance of 2000 lux, plants have 1.8 times more leaves and they also have a larger total leaf area of 2.2-3.2 times.

The data obtained indicate that the illuminance of 500 lux is below the light point of compensation in plants of the Indian borage, while in glossy forest grape and true cardamom the light intensity of 100 lux is below the light point of compensation.

When studying the effect of illuminance on phytoncidal activity, it was found that when illuminance was reduced to a minimum level of 100 lux, all studied plant species had no antimicrobial effect on microorganisms in the air environment.

Phytoncidal activity against air microorganisms was shown only by variants of true cardamom, that grown at an illuminance level of 500 lux. With this option, decreasing of the number of microorganisms by $15 \%$ is observed already at 4 hours after placing the plants in the box. At an illumination of 2000 lux, the number of microorganisms is reduced by $29 \%$. The phytoncidal activity of glossy forest grape in relation to the general microbial contamination of the air is $24 \%$ at illuminance of 2000 lux, and at 500 lux it decreases to $18 \%$.

The phytoncidal activity of Indian borage against the general microbial contamination of the air and Staphylococcus aureus is manifested after an hour of the plants being in the boxes. However, this effect is observed only in plants growing at an illuminance of 2000 lux, at a lower illuminance level of 500 and 100 lux, no phytoncidal activity of plants was observed. Phytoncidal activity in relation to the total microbial contamination of the air is $36 \%$, and in relation to Staphylococcus aureus strain $209-\mathrm{P}$ is $32 \%$.

The maximum phytoncidal activity of E. cardamomum, $P$. amboinicus and $R$. rhomboidea are observed at an illuminance of 2000 lux. Phytoncidal activity decreases 2-3 times with a decline in the illuminance level to 500 lux, and in Indian borage, as a more light-loving plant, it disappears altogether.

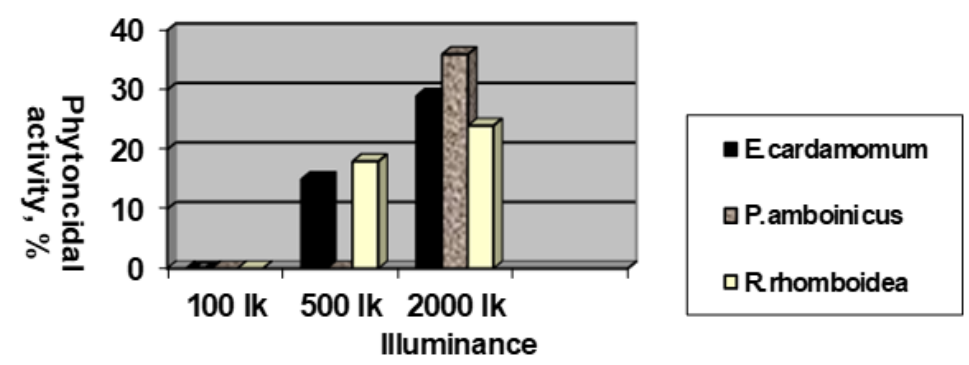

Fig. 1. Phytoncidal activity of three plant species 
Resistant houseplant species selected in accordance with the above criteria were used to formulate phytocompositions. Phytocompositions, consisting of 65-70 plants of 28-32 species, were placed by us in experimental classrooms of 11 schools in Moscow.

In the Secondary school, over the entire research period, when phytocompositions are used, the number of microorganisms decreases on average by $45 \%-58 \%$. Phytocompositions work more efficiently in the Primary school, where the number of microorganisms decreases on average by 5.2-7.3 times. This is, first of all, due to the fact that a constant contingent of younger pupils learn in the experimental classrooms in primary school. In secondary school, other pupils come to the experimental classrooms for the lesson, each time increasing the microbial contamination of the classroom air. Moreover, in schools, phytocompositions are effective not only in the spring during the growth phase of plants, when their phytoncidal activity in most cases increases, but also in late autumn. Allergenic manifestations were not observed in children and teachers.

Table 2. The influence of phytocompositions on reducing the number of microorganisms in the air of classrooms.

\begin{tabular}{|l|c|c|c|c|}
\hline \multirow{2}{*}{ Classroom } & \multicolumn{2}{|c|}{ April } & \multicolumn{2}{c|}{ November } \\
\cline { 2 - 5 } & $\begin{array}{c}\text { Number of colony- } \\
\text { forming units - } \\
\text { CFU, pcs / m3 }\end{array}$ & $\begin{array}{c}\text { Number of colony- } \\
\text { forming units - } \\
\text { CFU, pcs / m3 }\end{array}$ & $\begin{array}{c}\% \text { to } \\
\text { control }\end{array}$ \\
\hline \multicolumn{7}{|c|}{ Secondary school } \\
\hline Control (no plants) & 1995 & 100 & 2547 & 100 \\
\hline Experimental & 1101 & 55 & 1066 & 100 \\
\hline \multicolumn{7}{|c|}{ Primary school } & 3027 & 14 \\
\hline Control (no plants) & 1789 & 100 & 413 & 19 \\
\hline Experimental & 344 & 19 & & \\
\hline
\end{tabular}

The results obtained prove that by applying a new approach to the use of plants "ecological phytodesign" or "ecological aerofitotherapy", it is possible to create long-term effective phytocompositions with guaranteed positive results indoors. High-quality phytodesign of premises requires a lot of investment, so indoor plants should work in interiors for a long period of time. Knowledge of the influence of the parameters of growing indoor plants on their antimicrobial activity and gas-absorbing capacity will make it possible to intensify the use of plants in confined spaces and create cost-effective technologies for using plants with guaranteed results. The use of specially developed phytocompositions in classrooms makes it possible to improve the air environment of the premises by reducing microorganisms in them, to reduce the physical and mental fatigue of schoolchildren and teachers.

The work was performed within the framework of the research project No. 0576-2019-0008 of the Ministry of Science and Higher Education of the Russian Federation "Scientific formation, conservation and study of biocollections of various directions in order to create new medicines and improve the human environment".

\section{References}

1. V.B. Bogatyr, Indoor tropical and subtropical plant introduction (All-Union meeting, Chisinau, 29, 1989)

2. A. Tani, C. Nicholas Hewitt, Environ. Sci. Technol., 43 (21), 8338 (2009)

3. M. Giese, U. Bauer-Doranth, C. Langebartels, H. Sandermann jr, Plant Physiol., 104(4), 1301 (1994) 
4. R.A. Wood, M.D. Burchett, A. Alquezar, R. Orwell, J. Tarran and F. Torpy, Water Air Soil Poll., 175, 163 (2006)

5. R. Wood, R.L Orwell, J. Tarran, F. Torpy and M. Burchett, J. Hortic. Sci. Biotechnol., 77 (1), 120 (2002)

6. B.C. Wolverton, R. C. McDonald, E.A. Watkins, Econ. Bot., 38(2), 224 (1984)

7. B.C. Wolverton, A. Johnson and K. Bounds, Interior Landscape Plants for Indoor Air Pollution Abatement, Final Report, (NASA Stennis Space Centre MS, USA, 1989)

8. B.C.Wolverton, J.D. Wolverton, J. of Mississippi Acad. Sci., 38 (2), 11(1993)

9. N.V. Tsybulya, S.V. Kaznacheeva, Second republican conference on medical botany (Central repub. Botanical Garden, Kiev, 1988)

10. N.V. Tsybulya, T.D. Fershalova, Phytoncidal plants in the interior (air health with plants) (Novosibirsk book publish. house, Novosibirsk, 2000)

11. K.G. Tkachenko, N.V. Kazarinova, Greening problems in northern cities (Petrozavodsk, 1997)

12. J. Tarran, F. Torpy and M. Burchett, 6th International Conference On Indoor Air Quality, Ventilation \& Energy Conservation, - Sustainable Built Environment (Sendai, Japan, Oct., Vol III, 2007)

13. Yu.D. Gubernskyi, S.I. Ivanov, Yu.A. Rakhmanin, Ecology and hygiene of the living environment (GEOTAR-Media, Moscow, 2008)

14. A.N. Tsitsilin, Untraditional natural resources, innovative technologies and products (Publish. house of the Russian Acad. Natural Sciences, Moscow, 10, 2003,)

15. A.N. Tsitsilin, E.A. Motina, L.D. Shipulina, T.V. Fateeva, Reports of Timiryazev Agricultural Academy, 280, 251 (2008)

16. A.N. Tsitsilin, Houseplants for your health: cultivation and healing effects: the complete encyclopedia (Eksmo, Moscow, 2013)

17. E.Z. Tepper, V.K. Shilnikova, G.I. Pereverzeva, Practical works on microbiology (Kolos, Moscow, 1993) 